\title{
Marine Rapid Environmental Assessment in the Gulf of Taranto: a multiscale approach
}

\author{
Nadia Pinardi ${ }^{1,2}$, Vladyslav Lyubartsev ${ }^{2}$, Nicola Cardellicchio ${ }^{3}$, Claudio Caporale ${ }^{4}$, Stefania Ciliberti ${ }^{2}$, \\ Giovanni Coppini $^{2}$, Francesca De Pascalis ${ }^{6}$, Lorenzo Dialti ${ }^{4}$, Ivan Federico ${ }^{2}$, Marco Filippone ${ }^{4}$, Alessandro Grandi ${ }^{5}$, \\ Matteo Guideri ${ }^{4}$, Rita Lecci ${ }^{2}$, Lamberto Lamberti ${ }^{4}$, Giuliano Lorenzetti $^{6}$, Paolo Lusiani ${ }^{4}$, Cosimo Damiano Macripo $^{3}$, \\ Francesco Maicu ${ }^{6}$, Michele Mossa ${ }^{7}$, Diego Tartarini ${ }^{4}$, Francesco Trotta ${ }^{1}$, Georg Umgiesser ${ }^{6}$, and Luca Zaggia ${ }^{6}$ \\ ${ }^{1}$ Department of Physics and Astronomy, University of Bologna, Bologna, 40127, Italy \\ ${ }^{2}$ Centro EuroMediterraneo sui Cambiamenti Climatici, Bologna, 40128, Italy \\ ${ }^{3}$ Istituto per lo studio dell'Ambiente Marino Costiero-CNR, Taranto, 74100, Italy \\ ${ }^{4}$ Istituto Idrografico della Marina, Genoa, 16134, Italy \\ ${ }^{5}$ Istituto Nazionale di Geofisica e Vulcanologia, Bologna, 40128, Italy \\ ${ }^{6}$ Istituto di Scienze Marine-CNR, Venice, 30122, Italy \\ ${ }^{7}$ Department of Civil, Environmental, Building Engineering and Chemistry, Technical University of Bari, Italy
}

Correspondence to: Nadia Pinardi (nadia.pinardi@unibo.it)

Received: 15 May 2016 - Published in Nat. Hazards Earth Syst. Sci. Discuss.: 3 June 2016

Accepted: 2 November 2016 - Published: 9 December 2016

\begin{abstract}
A multiscale sampling experiment was carried out in the Gulf of Taranto (eastern Mediterranean) providing the first synoptic evidence of the large-scale circulation structure and associated mesoscale variability. The mapping of the mesoscale and large-scale geostrophic circulation showed the presence of an anticyclonic large-scale gyre occupying the central open ocean area of the Gulf of Taranto. On the periphery of the gyre upwelling is evident where surface waters are colder and saltier than at the center of the gyre. Over a 1-week period, the rim current of the gyre undergoes large changes which are interpreted as baroclinic-barotropic instabilities, generating small-scale cyclonic eddies in the periphery of the anticyclone. The eddies are generally small, one of which can be classified as a submesoscale eddy due to its size. This eddy field modulates the upwelling regime in the gyre periphery.
\end{abstract}

\section{Introduction}

Marine Rapid Environmental Assessment (MREA) was developed in the late 1990s to collect synoptic oceanographic data relevant for nowcasts, forecasts and derived applications (Robinson and Sellschopp, 2002). Situational sea awareness relies on observational and modeling information on the dynamical state of the sea in order to ensure safer and more efficient operations. MREA contributes to situational sea awareness by advancing the synoptic data acquisition for state estimation and forecasting. Opportunity observations, such as ARGO profilers, are normally not abundant enough to resolve the local scales of interest especially from a synoptic point of view. Thus MREA is one of the optimal experimental strategies to collect definitive evidence on ocean mesoscales for improving knowledge and forecasts.

The ocean is eventful and intermittent, and several processes generally contribute to its space-time variability. For its physical state variables, the space scales that MREA methodology targets are from a few hundred meters to several kilometers and temporal scales range from hours to days. Assuming a timescale of several days, the dominant variability is the large-scale general circulation and its mesoscale and submesoscale components (Thomas et al., 2008). At shorter timescales internal waves, upper mixed layer daily cycles and tides dominate the energy spectrum (Talley et al., 2011). MREA observations are necessary to resolve specific time and space scales of interest, thus increasing the usefulness of the observations for nowcasts and forecasts. 

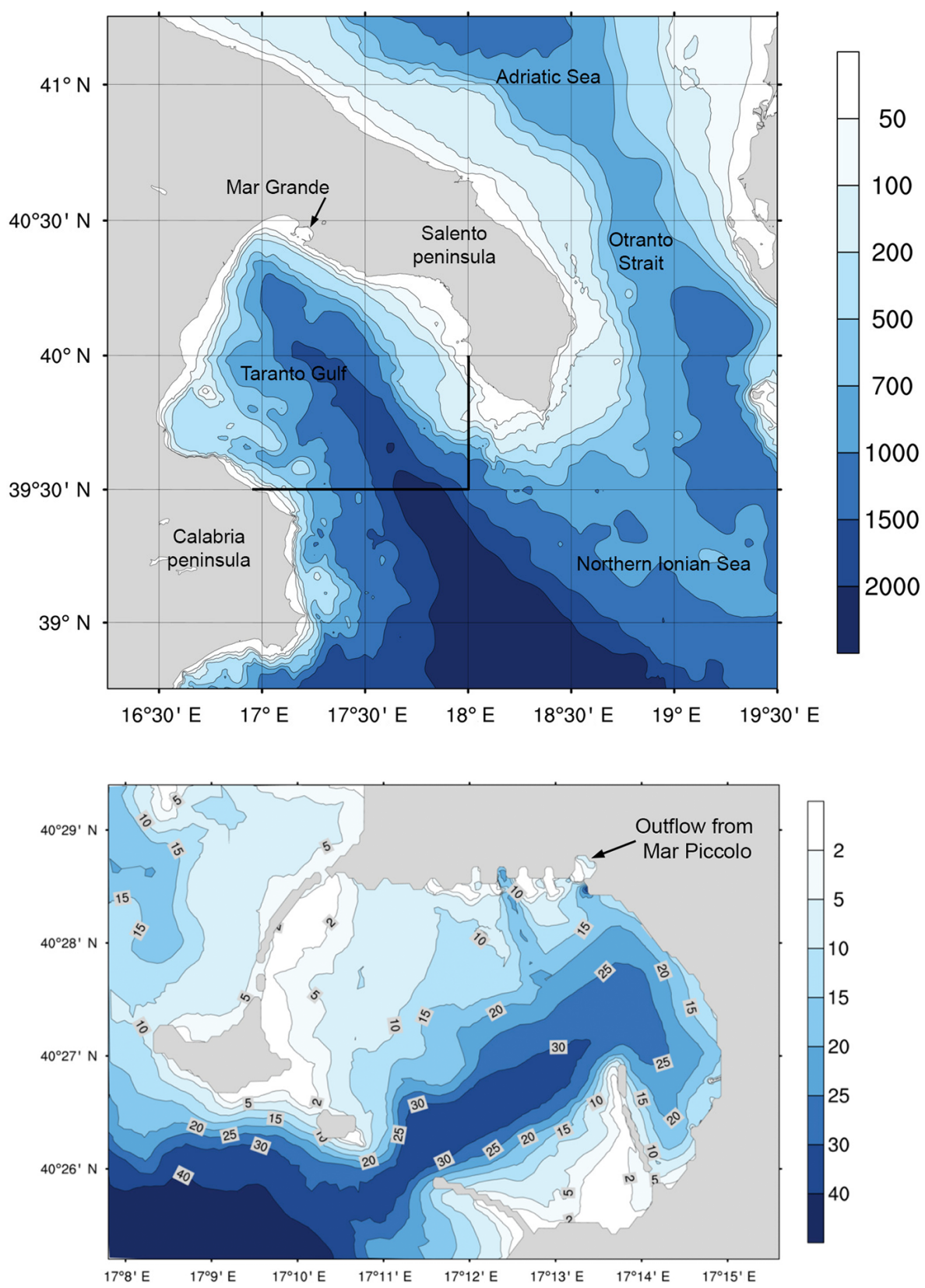

Figure 1. The Gulf of Taranto (upper panel) and the Mar Grande (lower panel) bathymetry and coastlines. In the lower panel, the connection of Mar Grande with Mar Piccolo is indicated.

The MREA methodology has three main components: (1) the observational strategy and ocean state estimation; (2) the nowcast and forecasting studies; (3) the forecast/analysis validation and reanalysis. In this paper we concentrate on the observational strategy and the objective mapping of the resulting circulation structures.

MREA has been implemented globally, in several regions, and adaptive sampling has also been developed (Lermusiaux, 2007, Frolov et al., 2014). Intermittency and multiscale processes have led to the concept of nested forecasts, which make use of optimized sampling networks to increase forecast accuracy. However, it is not yet clear if a regular grid ("lawnmower") survey, which is a "classical" strategy for synoptic ocean sampling, would be less efficient than adaptive path-planned surveys to map the synoptic variability with unknown field correlation scales.

We applied MREA to a little studied region of the world's ocean, the Gulf of Taranto in the northern Ionian Sea (Fig. 1). We use the classical, regular grid sampling strategy and explore the basic water mass properties as well as the 

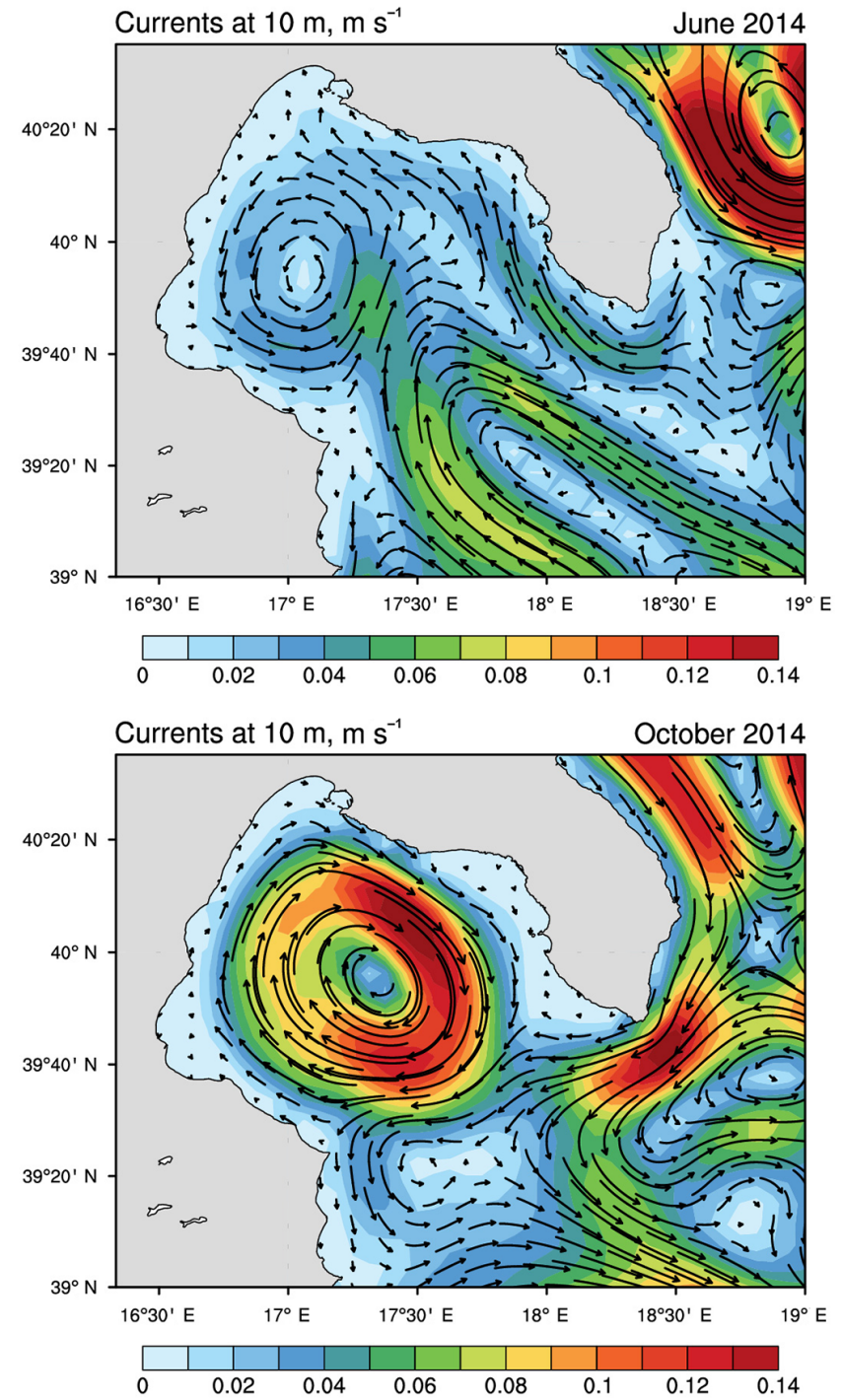

Figure 2. Monthly mean surface currents from reanalysis (Pinardi et al., 2015) in the Gulf of Taranto. Top panel: June 2014. Bottom panel: October 2014. The units are $\mathrm{m} \mathrm{s}^{-1}$ and the color indicates the amplitude.

geostrophic circulation. The insertion of these data in the large-scale operational model of the Mediterranean Forecasting System (Oddo et al., 2014) and in the nested highresolution model for the Gulf of Taranto are shown in a companion paper in this issue (Federico et al., 2016).

Here we analyze four surveys carried out in the area of the Gulf of Taranto from 1 to 10 October 2014 with the Italian Navy Survey Vessel Galatea and the RV Cerruti. A new multiscale sampling strategy was used to measure the temperature and salinity structure of the flow field from the open ocean to the shelf-coastal scales of the Gulf of Taranto (northwestern Ionian Sea in the Mediterranean Sea) and the coastal-harbor scales of Mar Grande (Fig. 1). The novelty of this data collection experiment is related to the different res-
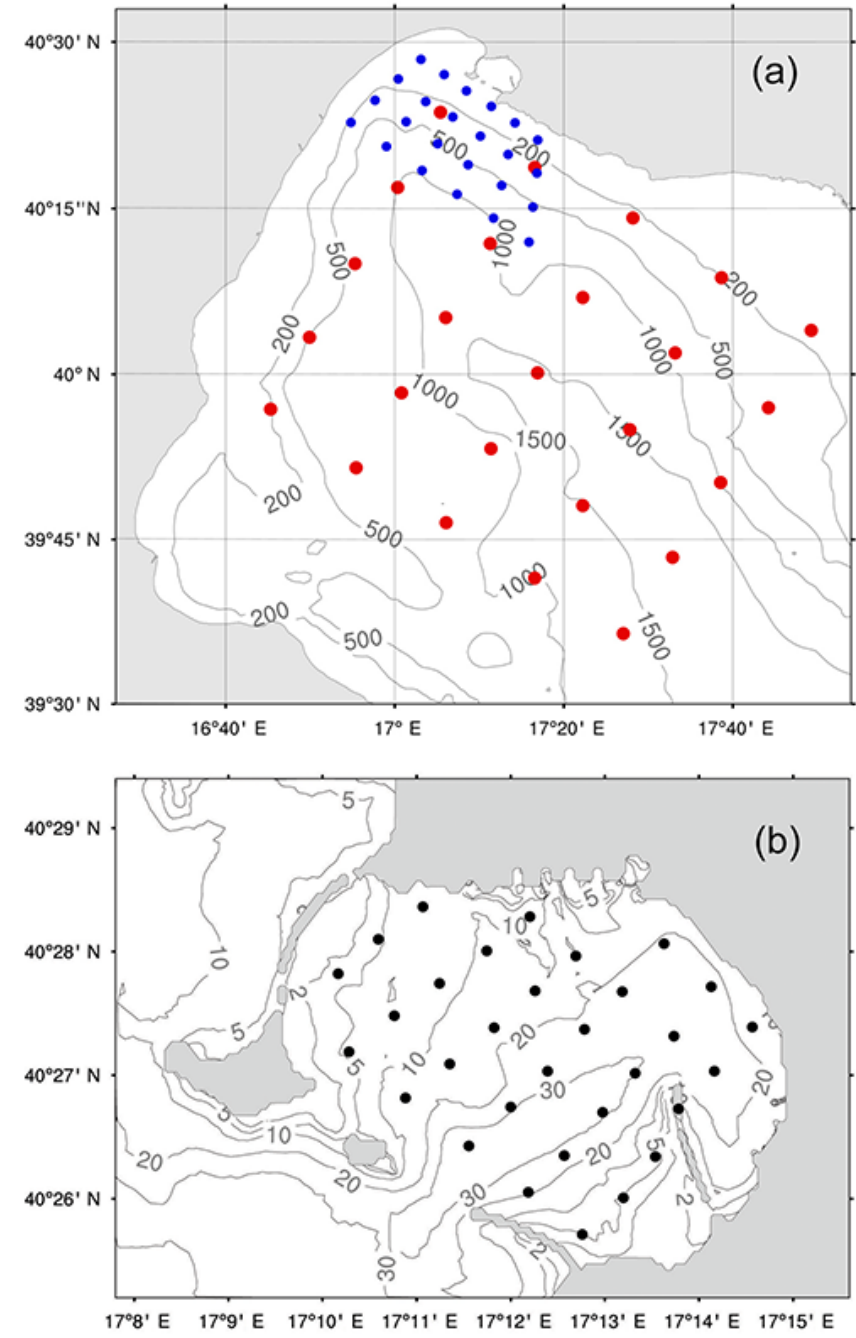

Figure 3. The four survey CTD station distributions: (a) the largescale survey LS1 and LS2 (red bullets) with the coastal-scale (CS1) survey in the northwestern corner (blue bullets); (b) the Mar Grande (MG) survey.

olution of the stations carried out in the different areas under the strict constraint of synoptic time coverage (3-4 days in the ocean).

The sampling strategy and the temperature and salinity data enables us to estimate the water masses in the area and construct dynamic height and the derived geostrophic circulation using objective analysis mapping techniques. This is the first time that the circulation has been mapped for the whole Gulf of Taranto with increasing resolution from the coasts to the open ocean and with synoptic timescale resolution. The usage of the MREA14 observations to assess model performances is given in two companion papers (Federico et al., 2016; Gaeta et al., 2016)

The paper is organized as follows: Section 2 describes the data collection methodology and Sect. 3 the water mass 

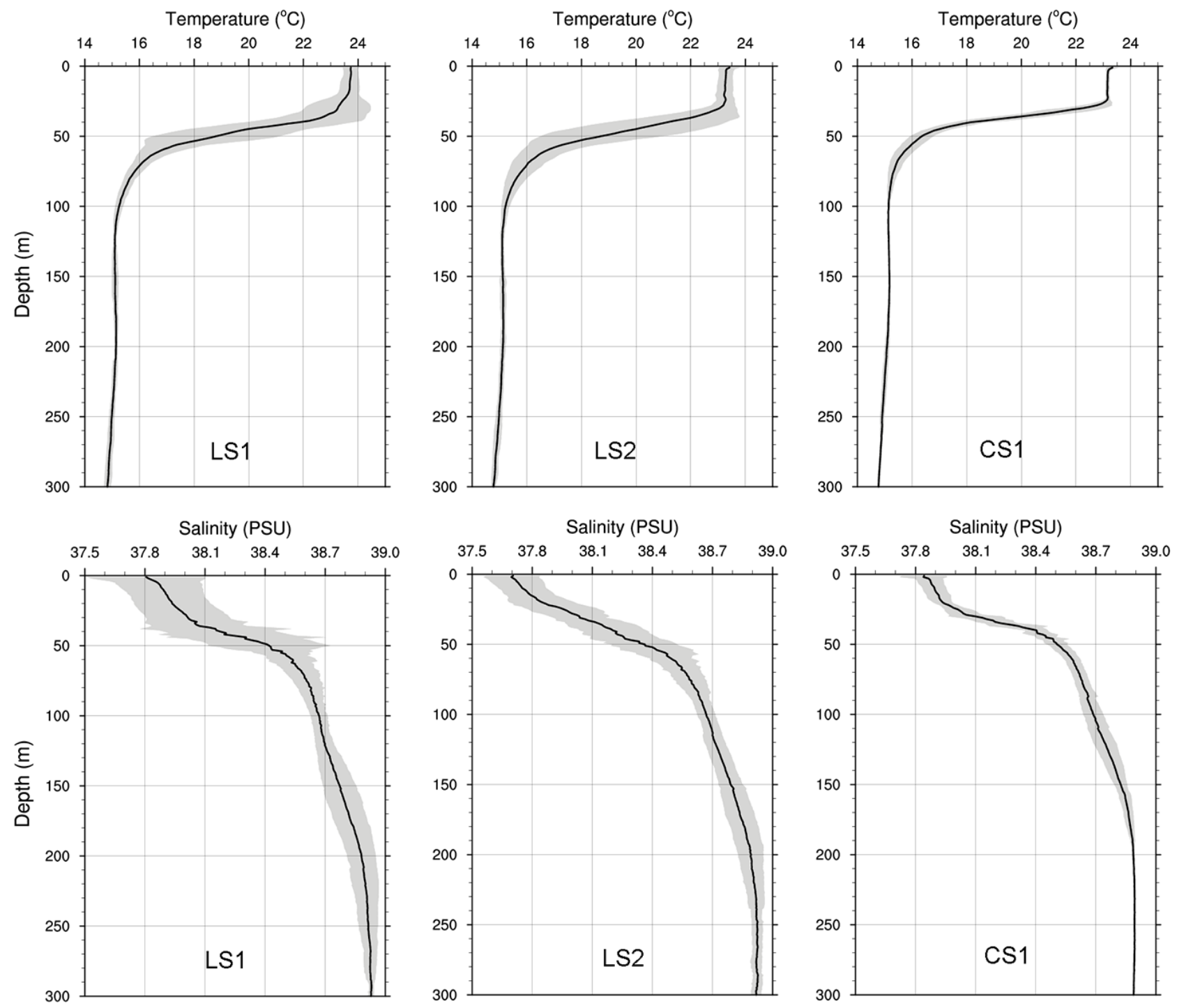

Figure 4. The station average temperature and salinity profiles for LS1 (left column), LS2 (central) and CS1 (right column) surveys. The grey shaded areas represent standard deviations of the survey station profiles from the mean.

analysis. Section 4 presents the dynamic height and the geostrophic circulation and Sect. 5 discusses the results.

\section{Circulation structure and data collection methodology}

The Gulf of Taranto is a deep, semi-enclosed ocean area in southern Italy encircled by two peninsulas, Salento and Calabria (Fig. 1). It is open to the northern Ionian Sea, and a deep trench of more than $2000 \mathrm{~m}$ connects it to the eastern Mediterranean Sea. The continental shelf area, considered as the area from the coasts to the $200 \mathrm{~m}$ depth contour, occupies only $10 \%$ of the total Gulf area. The shelf is wider on the Salento than the Calabria side and a $7.5 \mathrm{~km}$ wide sheltered elliptical embayment, called the Mar Grande, opens in the northeastern part of the Gulf (Fig. 1).

From a large-scale point of view, the mean circulation in the area can be assessed by taking the current fields from a reanalysis product (Pinardi et al., 2015) that does not contain the MREA data. The surface circulation (Fig. 2) is anticyclonic in October 2014, while in June 2014 it is cyclonic. This opposite circulation pattern is probably connected to the different Western Adriatic Coastal Current (WACC; Guarnieri et al., 2013), Northern Ionian Sea outflow-inflow system in the 2 months and the local atmospheric forcing.. One of the major aims of the MREA experiment was to verify the October circulation shown in Fig. 2.

The Gulf of Taranto is a deep semi-enclosed sea with lateral water exchanges with the Ionian Sea. The seasonally dif- 
Table 1. number of CTD stations carried out during the surveys at large, shelf and harbor scales.

\begin{tabular}{lrrl}
\hline $\begin{array}{l}\text { Cruise } \\
\text { name }\end{array}$ & $\begin{array}{r}\text { Number of } \\
\text { CTD } \\
\text { stations }\end{array}$ & $\begin{array}{r}\text { Data collection } \\
\text { time period } \\
\text { (days) }\end{array}$ & \\
\hline LS1 & 26 & 3 & 1 Oct at $15: 30$ to 3 Oct at 24:00 \\
MG1 & 31 & 1 & 5 Oct from $7: 15$ to $11: 30$ \\
CS1 & 24 & 1 & 8 Oct from 16:00 to 20:20 \\
LS2 & 25 & 3 & 9 Oct from 01:00 to 10 Oct at 24:00 \\
\hline
\end{tabular}

ferent circulation of the Gulf of Taranto described above may lead to changes in the inflow-outflow structure. In the anticyclonic case, it is likely that vertically stratified water masses enter the Gulf from the western side (Calabria in Fig. 1) and exit from the Salento side (eastern side, see Fig. 1). We argue that Mar Grande could have both lateral and vertical exchanges, as classified by Cessi et al. (2014). The MREA experiment partly clarified these questions.

Very few CTD observations in the past have been reported in the Gulf of Taranto and none with a synoptic coverage. Our goal was mainly to carry out the first survey of the thermohaline properties of the area with synoptic coverage at three different scales: large, shelf and harbor scale (Mar Grande). Based on the large-scale flow structure in Fig. 2, the four surveys were planned and implemented following the schemes presented in Fig. 3 and described in Table 1.

The large-scale surveys (LS1 and LS2) were carried out over 3 days, a quasi-synoptic timescale, in an area which is on average $800 \mathrm{~m}$ deep. The stations were repeated in LS2 in order to understand large-scale temperature and salinity changes on a weekly basis. The mean station distance between stations was $16 \mathrm{~km}$, which is about the Rossby radius of deformation for the eastern Mediterranean (Hecht et al., 1988). This spacing was chosen as a good compromise between the horizontal resolution and the time needed to cover the area synoptically.

The shelf-scale survey, CS1, was carried out in the northeastern Gulf of Taranto, an extended shelf area of the Gulf (Fig. 1). The mean distance between the stations was $5 \mathrm{~km}$ and the mean depth of the area was $400 \mathrm{~m}$. The MG1 survey covers the shelf area of the Mar Grande which is a heavily human impacted harbor area. The distance between stations in the Mar Grande is $\sim 1 \mathrm{~km}$ and the mean depth was $15 \mathrm{~m}$.

All measurements were carried out with Idronaut CTD 316Plus on board of the RV Galatea for LS1, CS1 and LS2 and the RV Cerruti for MG1.

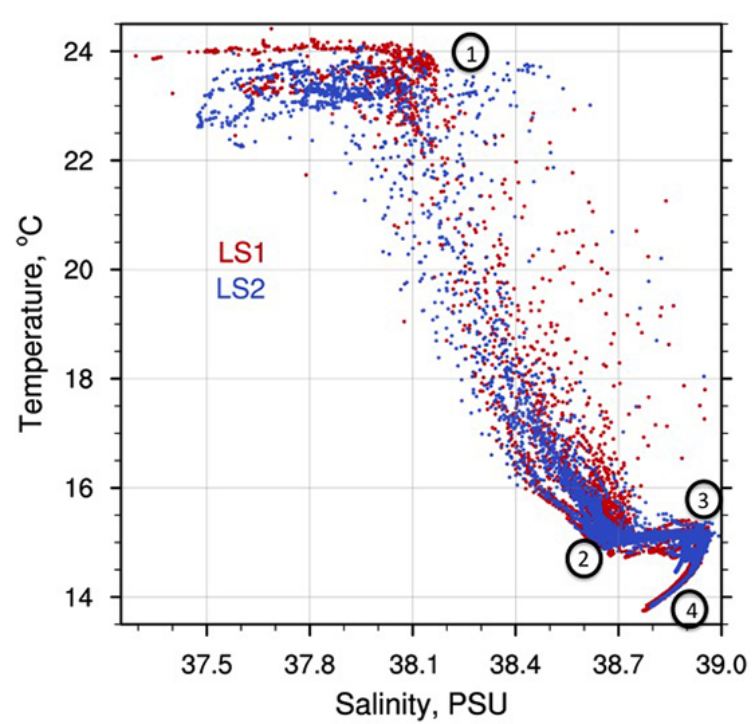

Figure 5. T-S diagram for all the LS1-LS2 profiles, covering the depths of $1-900 \mathrm{~m}$ (the deepest point is in the central trench of the Gulf of Taranto, see Fig. 1). Numbers refer to the four water mass types found in the profiles and discussed in the text.

\section{Thermohaline structure of the Gulf of Taranto and Mar Grande}

\subsection{Vertical structure of temperature, salinity and density}

The LS1, LS2 and CS1 mean vertical profiles are shown in Fig. 4. The mean profile is estimated by taking the arithmetic average of observational points across the profiles which are defined on a $1 \mathrm{~m}$ regular vertical grid. The temperature structure is typical of the end-of-summer stratification in the eastern Mediterranean, i.e., a mixed layer down to $30 \mathrm{~m}$ and a seasonal thermocline with a temperature gradient of about $10^{\circ} \mathrm{C}$. Between 100 and $300 \mathrm{~m}$ it is possible to detect the subsurface salinity maximum characteristic of the Modified Levantine Intermediate Water (MLIW; Theocharis et al., 1993), which reaches slightly higher values than 38.9 PSU in this region. The salinity at the surface does not have a particular mixed layer structure, but it decreases smoothly between the surface and $100 \mathrm{~m}$. The low salinity values at the surface (37.8 PSU) could indicate surface waters of an Adriatic or Atlantic origin (Atlantic Modified Waters, AMW, Theocharis et al., 1993) because there are no large rivers discharging in this area. Differences between LS1, LS2 and CS1 are evident in the surface salinities: CS1 surface salinities are larger than LS1 and LS2 suggesting the upwelling of saltier waters from the subsurface. Further evidence of upwelling is given in Sect. 3.2.

Figure 5 shows a $T-S$ diagram of the LS1 and LS2 profiles to better identify the water masses and types. Some of the profiles extended to $900 \mathrm{~m}$ depth in the central Gulf of 

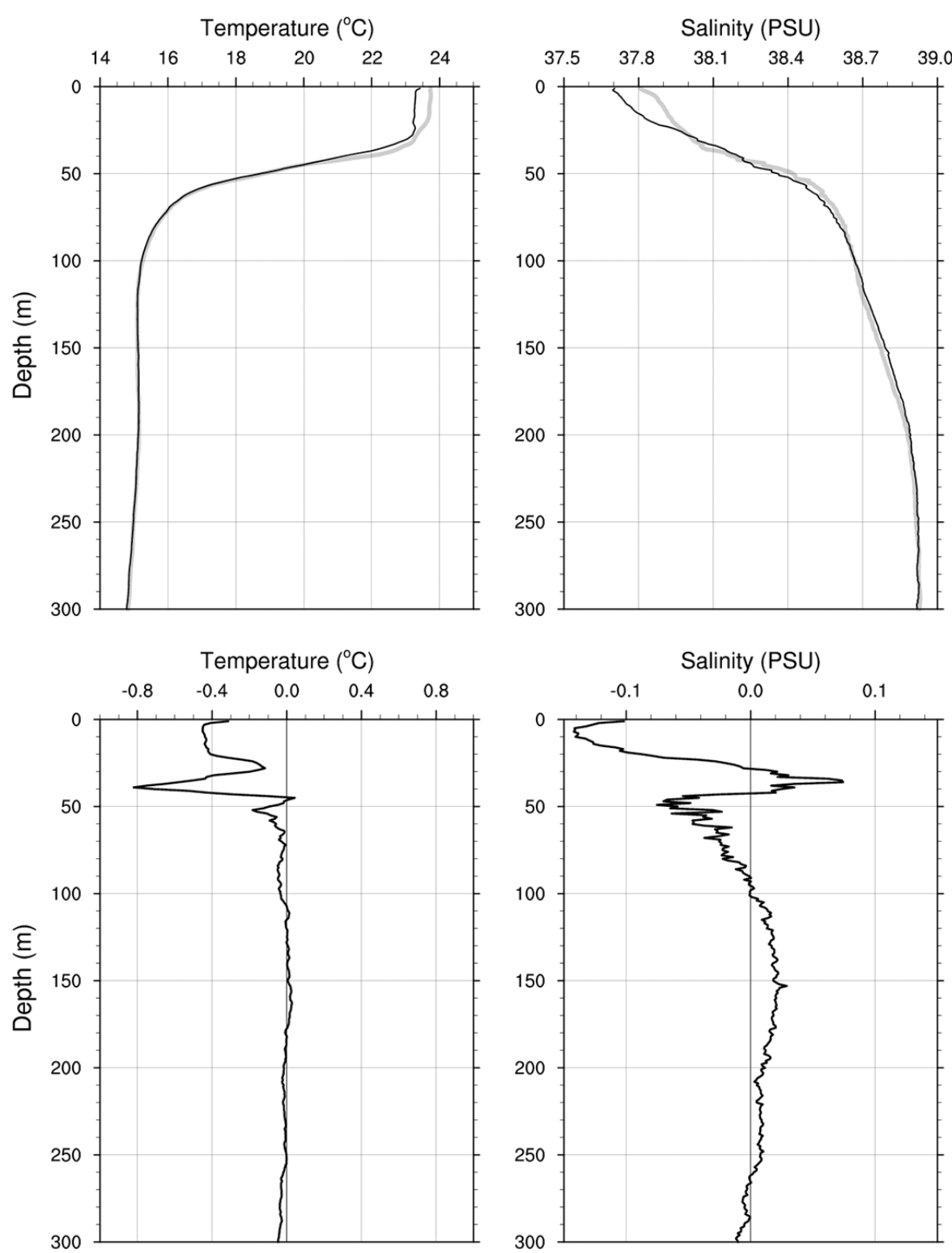

Figure 6. Superimposed mean temperature and salinity LS1 and LS2 profiles and differences. Top left: LS1 (grey line) and LS2 (black line) mean temperature profiles. Top right: LS1 (grey line) and LS2 (black line) mean salinity profiles. Bottom left: LS2-LS1 mean temperature difference. Bottom right: LS2-LS1 mean salinity difference.

Taranto trench (Fig. 1); thus four water masses can be detected, one more with respect the three already discussed for the first $300 \mathrm{~m}$. The first water mass is the surface water mass, indicated by water type 1 in Fig. 5, corresponding to low salinity and almost constant temperature. The second is the thermocline water type (number 2 in Fig. 5) due to the mixing of the surface waters and MLIW as shown clearly by the clustering of the $T-S$ points around a line joining the two water types. Furthermore, MLIW (point 3 in Fig. 5) is now clearly detectable with a salinity and temperature increase with respect to the thermocline water mass type. Finally a deep water mass type (4 in Fig. 5) is also evident, with tem- peratures lower than $14{ }^{\circ} \mathrm{C}$ and relatively low salinities, probably of Adriatic origin.

The interesting features of the LS1 and LS2 survey are the changes that occur over a 1-week period, between the two cruises, in the first $100 \mathrm{~m}$ of the water column (Fig. 6). LS2 was colder and fresher than LS1 by approximately $0.5^{\circ} \mathrm{C}$ and $0.1 \mathrm{PSU}$ and the mixed layer depth had decreased by about $5 \mathrm{~m}$, leading to a $0.8^{\circ} \mathrm{C}$ difference in temperature at $40 \mathrm{~m}$ (Fig. 6). The weather conditions deteriorated after 4 October and large winds developed on 5 October while precipitation started 3 October and continued until 5 October (Fig. 7). 


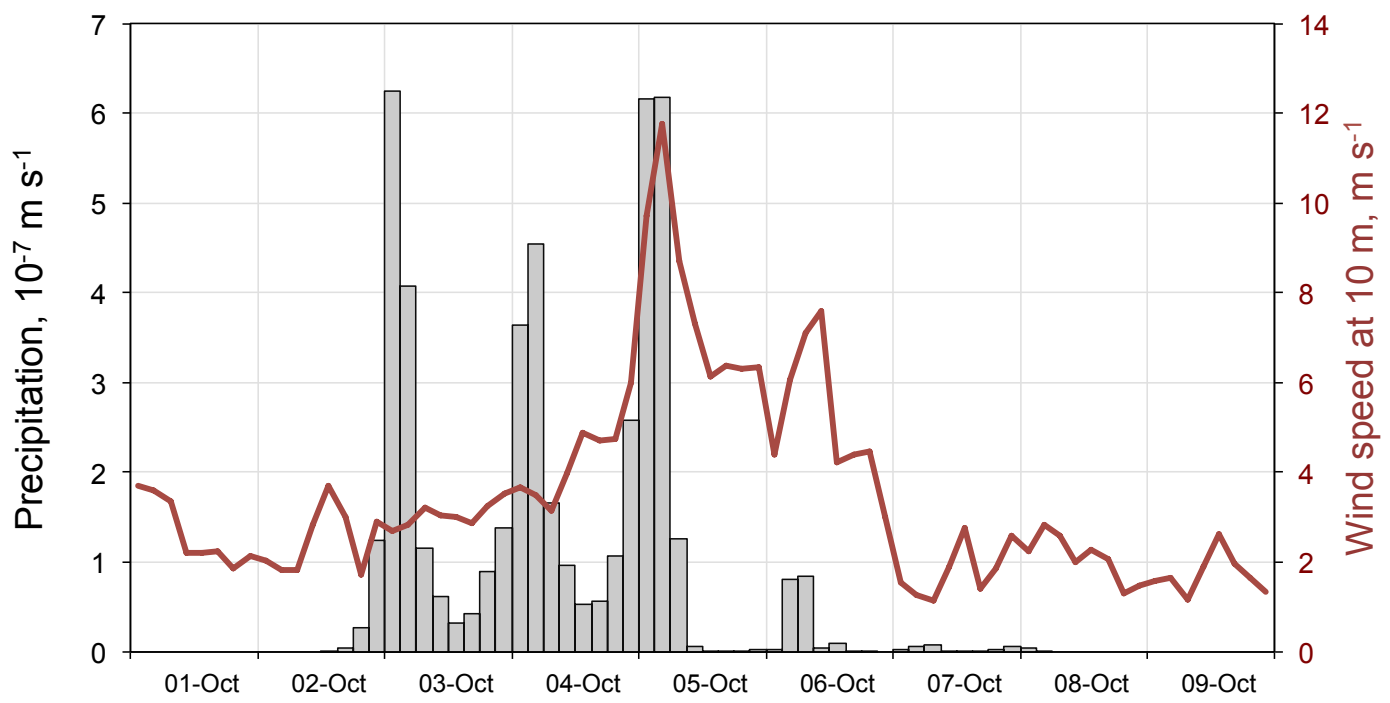

Figure 7. Area average precipitation and $10 \mathrm{~m}$ wind magnitude during the cruise period from a limited area high resolution weather forecasting model of the Mediterranean Sea (Bonavita et al., 2008). Precipitation is visualized as an histogram (units of $\mathrm{m} \mathrm{s}^{-1}$ ) and wind magnitude is the red curve (units of $\mathrm{ms}^{-1}$ ).

Such atmospheric forcing changes can justify the temperature and salinity decrease at the surface, as discussed below.

From the difference in salinity between LS1 and CS1, we can approximately compute the value of the precipitation required for such a change at the surface. Knowing that the surface water flux due to precipitation, $P$, amounts to a change in salt water flux that is

$K_{\mathrm{V}} \frac{\Delta S}{\Delta z}=-S_{o} P$.

Assuming $K_{\mathrm{V}}$, the vertical diffusivity, equal to $10^{-3} \mathrm{~m}^{2} \mathrm{~s}^{-1}$, $\Delta z=20 \mathrm{~m}, S_{0}=37.7 \mathrm{PSU}, \Delta S=-0.1$, we obtain $P=$ $1.310^{-7} \mathrm{~ms}^{-1}$, which is close to the time average value of precipitation, $P=1.410^{-7} \mathrm{~ms}^{-1}$, shown in Fig. 7 for this period.

The thermocline extension is better represented by the profile of Brunt-Väisälä frequency represented in Fig. 8. Typical values are in the range of $3-15$ cycles $^{-1}$, which is relatively large for the open ocean (Talley et al., 2011), indicating that the water column is stably stratified. The maximum BruntVäisälä frequency is reached at a $40 \mathrm{~m}$, which is approximately the middle depth of the region of maximum temperature gradients in Fig. 4 and a depth located within the thermocline water mass layer shown in Fig. 5. Taking 3 cycles $\mathrm{h}^{-1}$ as the low value to mark the transition to intermediate waters, the thermocline then extends between 30 and $100 \mathrm{~m}$.

Lastly we describe the thermal and haline structure of the Mar Grande. Figure 9 shows the temperature, salinity and density structure of the water column, average from all stations. The salinity values in the first $5 \mathrm{~m}$ of the water column are 0.4 PSU lower than in CS1 and LS1/LS2 indicating the source of the low-salinity waters from the Mar Piccolo, located northeast of the Mar Grande (Fig. 1). Between 6 and $9 \mathrm{~m}$ salinity values are similar to the values in LS1/LS2, marking the entrance of the shelf and open ocean waters from the Gulf of Taranto. As expected, the density is uniform since the harbor is a partially confined, shallow water area where turbulent mixing renders the whole water column uniform.

\subsection{Objective mapping of the temperature and salinity fields}

In this section we describe the horizontal distribution of temperature and salinity at two different depths, one in the center of the mixed layer $(10 \mathrm{~m})$ and the other in the middle of the thermocline $(60 \mathrm{~m})$. The mapping was carried out by an objective analysis (OA) technique (Bretherton, 1976; Carter and Robinson, 1987) described briefly in the Appendix. For the mapping, CS1 and LS2 networks were combined in order to give an overall picture of the temperature and salinity structures from the shelf to the open ocean. CS1 was merged only with LS2 since it was taken at the beginning of the LS2 survey and the combination was still synoptic.

Figure 10 shows the upper mixed layer temperature and salinity mapping for LS1 and LS2 + CS1. During the LS1 cruise, from 1 to 3 October 2014, the temperature and salinity mixed layer structure was dominated by a frontal structure (F1), separating colder and saltier waters near the shelf escarpment from higher-temperature, fresher waters offshore, in the open ocean areas of the Gulf of Taranto. Three cold core eddies $(\mathrm{C} 1, \mathrm{C} 2$ and $\mathrm{C} 3$ in Fig. 10) are present north of the frontal structure. After 1 week, during the CS1 + LS2 cruises from 8 to 10 October 2014, the temperature front disappeared and smaller eddies formed. The northernmost cyclonic eddy (C4) has a diameter less than $10 \mathrm{~km}$ and was produced in the mapping by two stations in the CS1 network. 

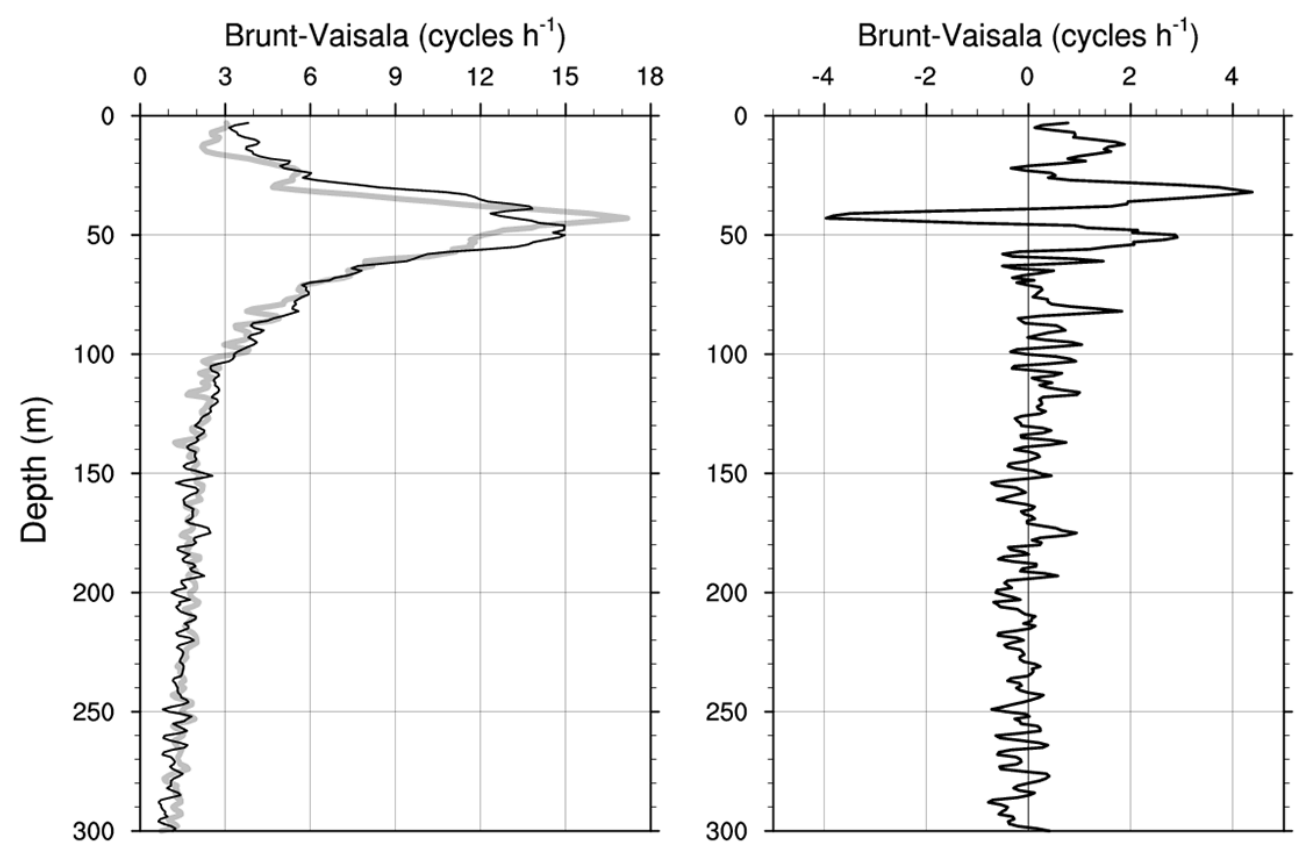

Figure 8. Left panel: mean Brunt-Väisälä frequency (cycles $\mathrm{h}^{-1}$ ) for LS1 (grey) and LS2 (black) surveys. Right Panel: LS2 minus LS1 Brunt-Väisälä profile.
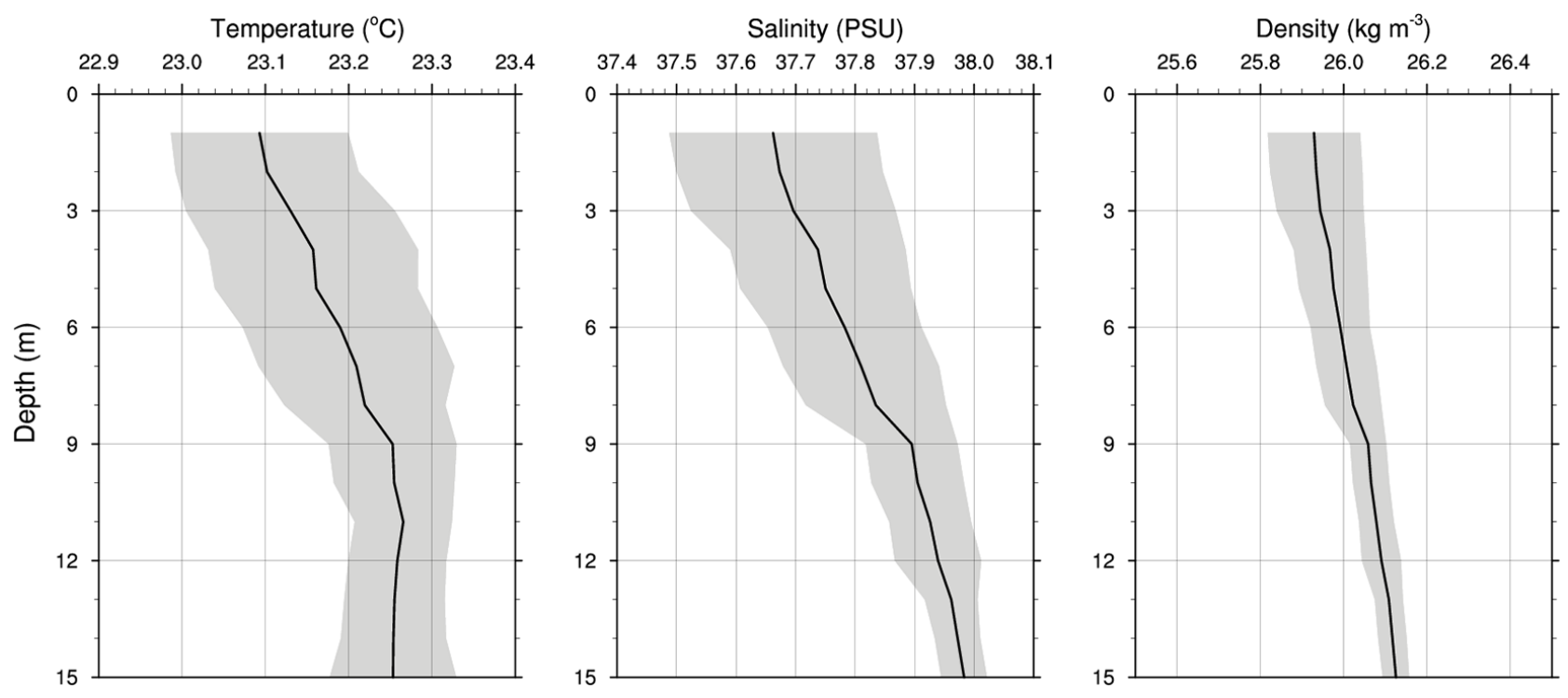

Figure 9. Mar Grande horizontal average temperature (left), salinity (center) and density (right) profiles for 5 October 2014. The grey shaded areas represent standard deviations from the mean.

This eddy was mixed layer intensified and it had a diameter of about one-fifth of the one associated with eastern Levantine mesoscale eddies (Hecht et al., 1986).

In the seasonal thermocline, the temperature and salinity structure was dominated by a large-scale anticyclonic gyre in the center of the Gulf of Taranto (Fig. 11). This gyre was already evident in the October 2014 reanalysis flow field of Fig. 2. This is, however, the first direct evidence of the anti- cyclonic structure of the Gulf of Taranto circulation for October. The anticyclone was defined by the observations as the area limited by the largest open ocean temperature and salinity gradients. It appeared that the anticyclone strengthened between LS1 and LS2, forming meanders and intensified gradient segments. In the periphery of the anticyclonic rim current, upwelling is evident because the water is colder and saltier than inside the anticyclone (Fig. 11). At $60 \mathrm{~m}$ 

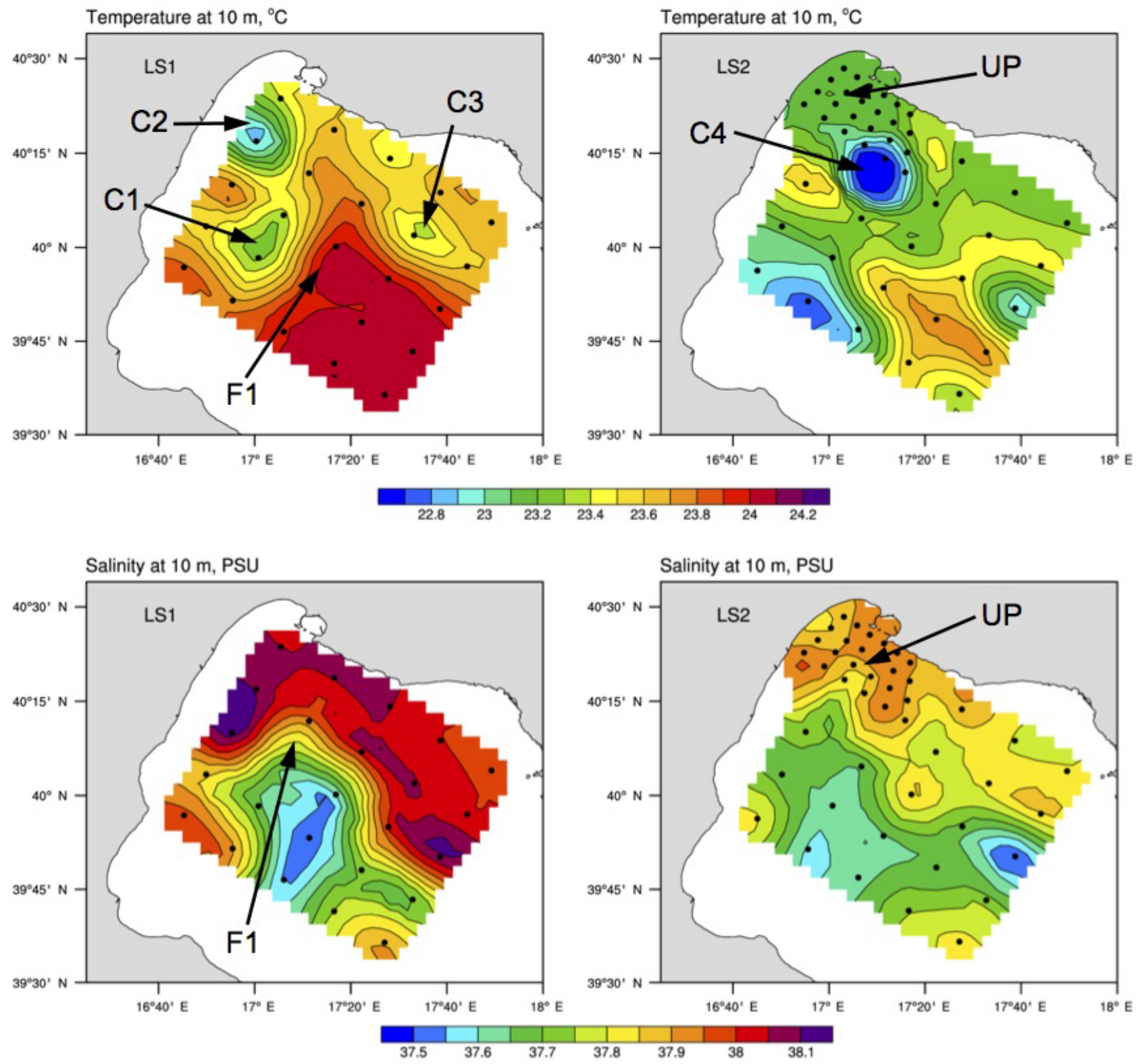

Figure 10. Temperature and salinity objective mapping at $10 \mathrm{~m}$. Left top and bottom panel: LS1 temperature and salinity fields. Right top and bottom panel: LS2 temperature and salinity fields. Symbols indicate four cold core eddies (C1, C2, C3, C4), the temperature and salinity front (F1) and the upwelling area (UP).

depth only the C3 cyclonic eddy is evident. Between LS1 and CS1 + LS2 cruises the upwelled cold and salty waters on the northeastern side of the Gulf of Taranto anticyclone had changed considerably, below and around the small-scale cyclonic mixed layer eddy (Fig. 10, C4).

In order to better represent the upwelling phenomena occurring at the periphery of the gyre in the Gulf of Taranto, Fig. 12 shows a section of the temperature and salinity fields. The section shows that between LS1 and LS2 the anticyclone deepened at the center and stronger upwelling occurred at its borders. The mixed layer partly restratified in tempera- ture, which is consistent with submesoscale dynamics in the mixed layer (Thomas et al., 2007).

Finally the temperature and salinity mapping in the Mar Grande is shown in Fig. 13. Both surface temperature and salinity were characterized by a frontal region in the middle of the area, produced by the inflowing fresher and colder waters from the Mar Piccolo (Fig. 1). Near the bottom and at mid-depth the waters were of offshore origin and upwelling was detected in the northeastern part of the area probably as part of the vertical estuarine circulation structure, as described in modeling studies (Gaeta et al., 2016). The MREA 

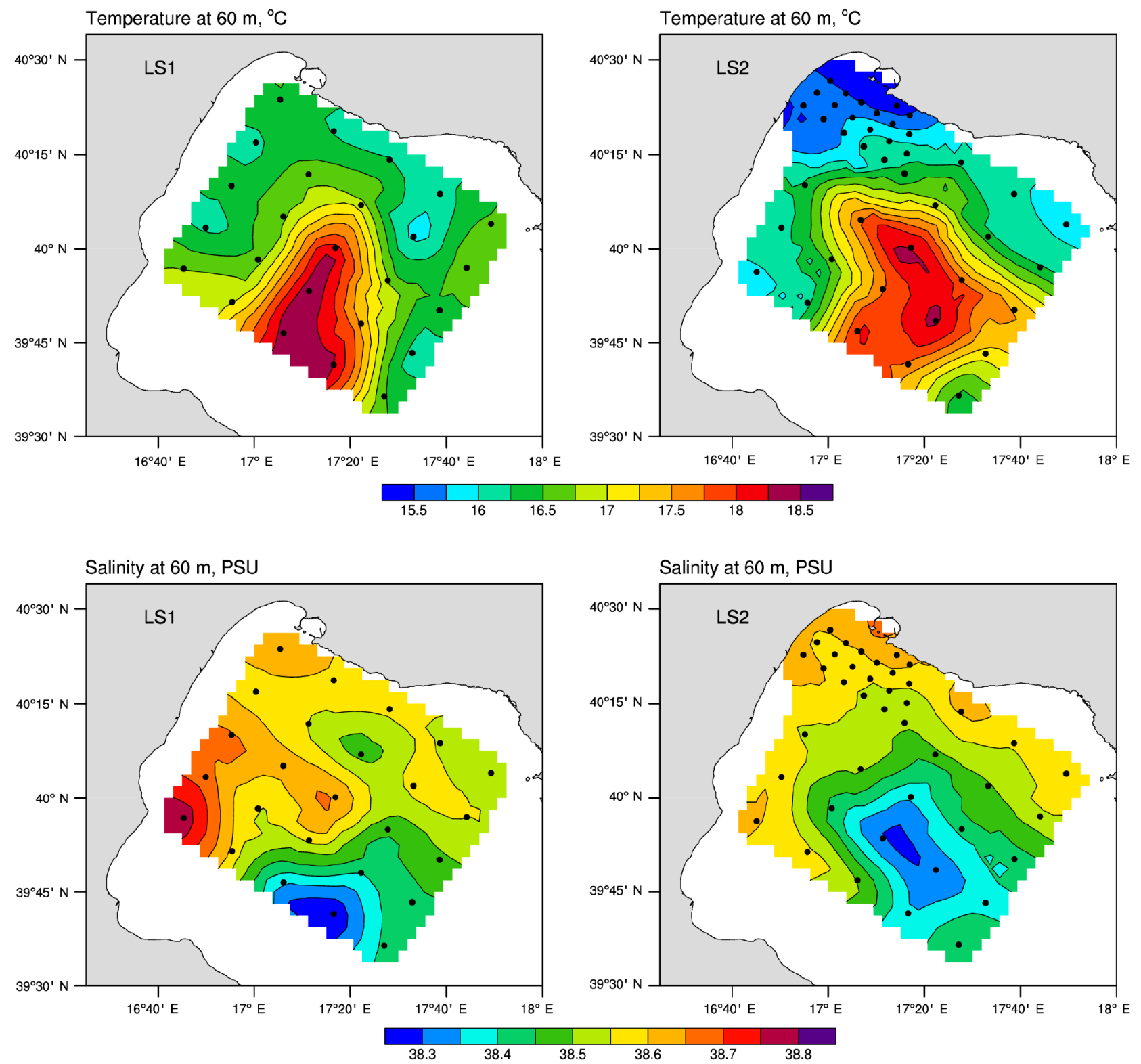

Figure 11. Seasonal thermocline $(60 \mathrm{~m})$ temperature (top) and salinity (bottom) mapping for LS1 (left panel) and LS2 (right panel).

strategy in the Mar Grande finally elucidated the estuarine nature of the circulation in the Mar Grande at unprecedented resolution.

\section{Circulation in the Gulf of Taranto in October 2014}

A dynamic height at $10 \mathrm{~m}$ with respect to a reference level of $100 \mathrm{~m}$ was computed from the density profiles (Fig. 14). This shallow reference level was chosen in order to capture part of the connections between the open ocean and the shelf.

The dynamic height shows the large-scale anticyclonic gyre of the Gulf of Taranto in a similar position to that found in the October 2014 reanalysis picture in Fig. 2. The pe- riphery of the anticyclone was characterized by the cyclonic eddy corresponding to C3 of Fig. 10 in LS1 and by an eddylike upwelling area in LS2, located in the area of the cyclonic eddy C4 in Fig. 10. Between LS1 and LS2, the anticyclone changed noticeably in shape and intensity, strengthening from LS1 to LS2. These changes are likely due to dynamical instabilities of the anticyclone rim current that modulate the upwelling at the periphery.

Figure 15 shows the geostrophic velocities computed from the dynamic height. The LS1 surface currents, turning clockwise around the anticyclonic gyre, are characterized by jets, i.e., intensified rim current segments. In LS1 one of these jets developed between the anticyclone and the eastern side cy- 

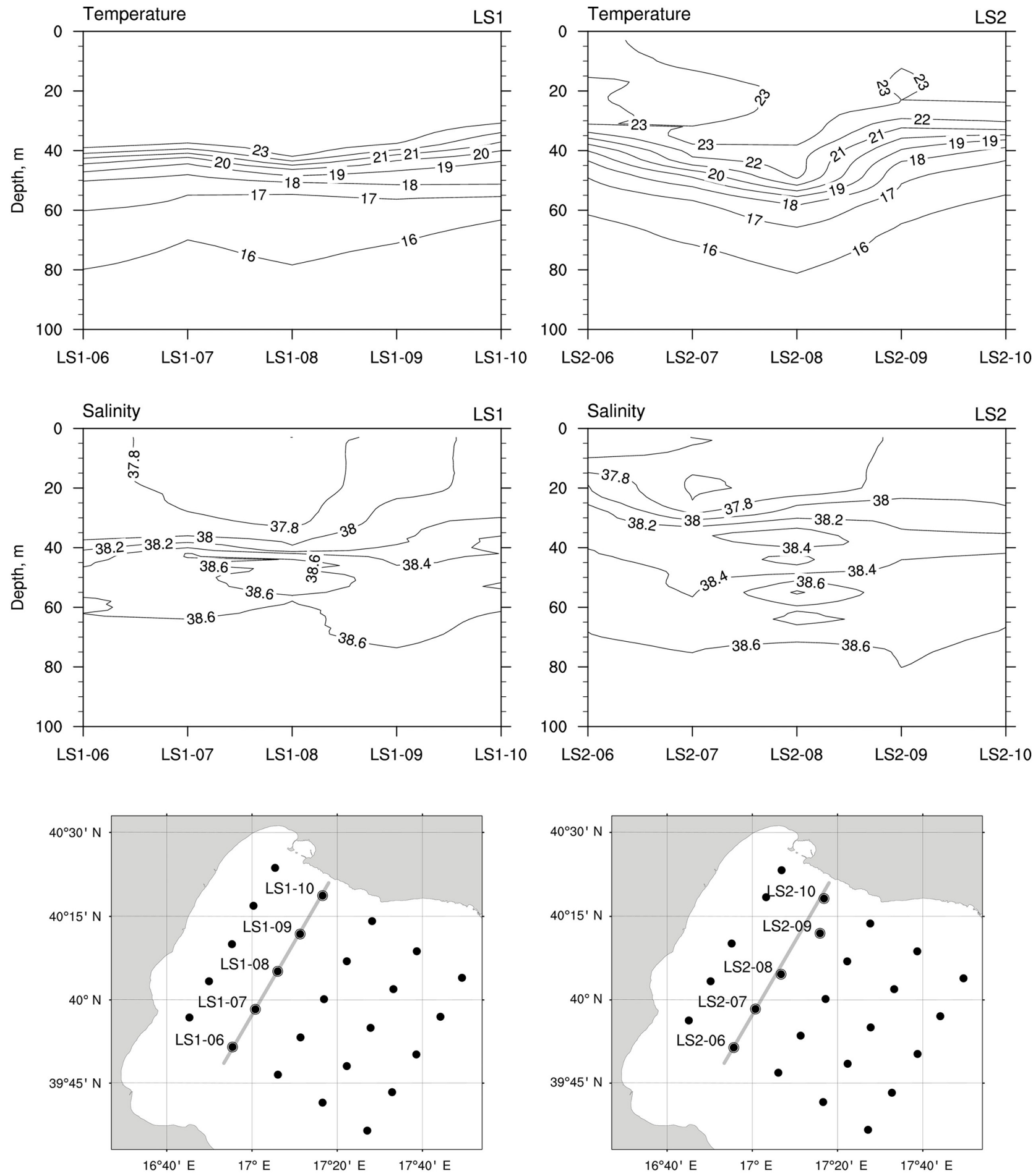

Figure 12. Temperature (top) and salinity (intermediate) transects for LS1 (left) and LS2 (right). The LS1 and LS2 transect stations are illustrated in the two bottom panels.

clonic eddy, corresponding to C3 in Fig. 10. At LS2 + CS1, the gyre underwent considerable changes in the jets strength because the rim current was meandering, which is a manifestation of baroclinic-barotropic instability and eddy growth.
On the northeastern side of the anticyclonic gyre, the cyclonic eddy $\mathrm{C} 4$ of Fig. 10 emerged as a circulation structure in Fig. 15. The rim current of the gyre meandered around this cyclonic and a new jet developed, with velocities of the 

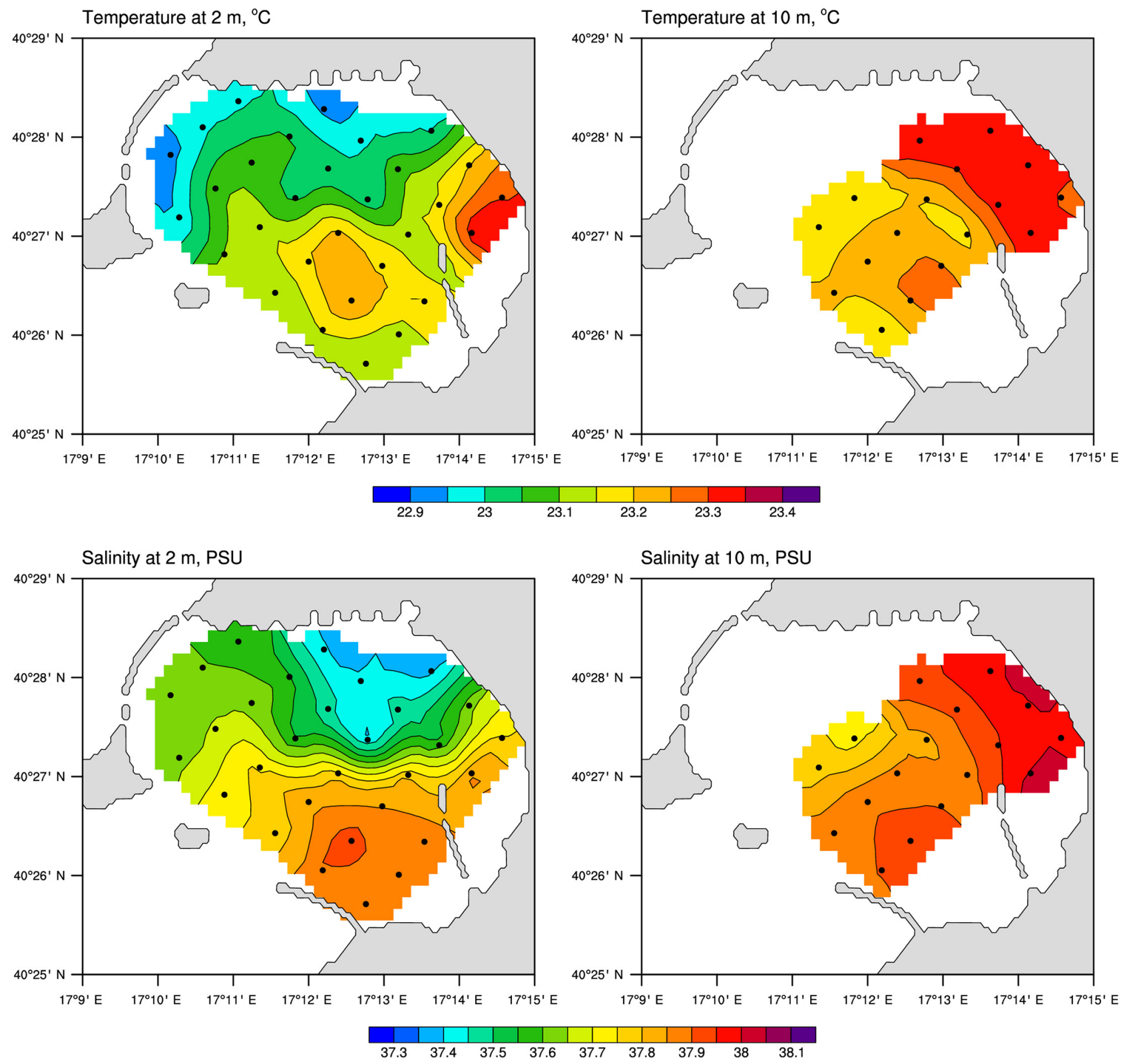

Figure 13. Mar Grande near-surface ( $2 \mathrm{~m})$ and near-bottom (10 m) mapping of temperature and salinity fields for 5 October 2014.

order of $40 \mathrm{~cm} \mathrm{~s}^{-1}$. This cyclonic eddy was much smaller than the LS1 C3 eddy, about $5-10 \mathrm{~km}$ in diameter, probably generated by a frontogenesis/cyclogenesis event along the anticyclonic rim current. The submesoscale field was mapped in the Mediterranean Sea (Bouffard et al., 2012) for the Balearic northern current. Here for the first time we found the growth of a small-scale submesoscale eddy at the border of a large, subbasin-scale gyre as a result of the meandering of its rim current. Notwithstanding the different generation mechanisms in different parts of the basin, we believe this is an evidence of pervasive submesoscale dynamics in the Mediterranean Sea.

\section{Discussion and conclusions}

We carried out a multiscale sampling experiment in the Gulf of Taranto. Our experiment provided the first synoptic evidence of the large-scale circulation structure and associated mesoscale variability. We used a classical sampling strategy, with a regularly spaced station network in three different subareas of the Gulf. In the open ocean, the LS1 and LS2 sampling was carried out at $15 \mathrm{~km}$ resolution over 3 days, while in the northeastern shelf area the station spacing was about $5 \mathrm{~km}$ and the 24 stations were carried out in 1 day. Finally the Mar Grande harbor scale was sampled at $1 \mathrm{~km}$ resolution and the sampling required $12 \mathrm{~h}$. 


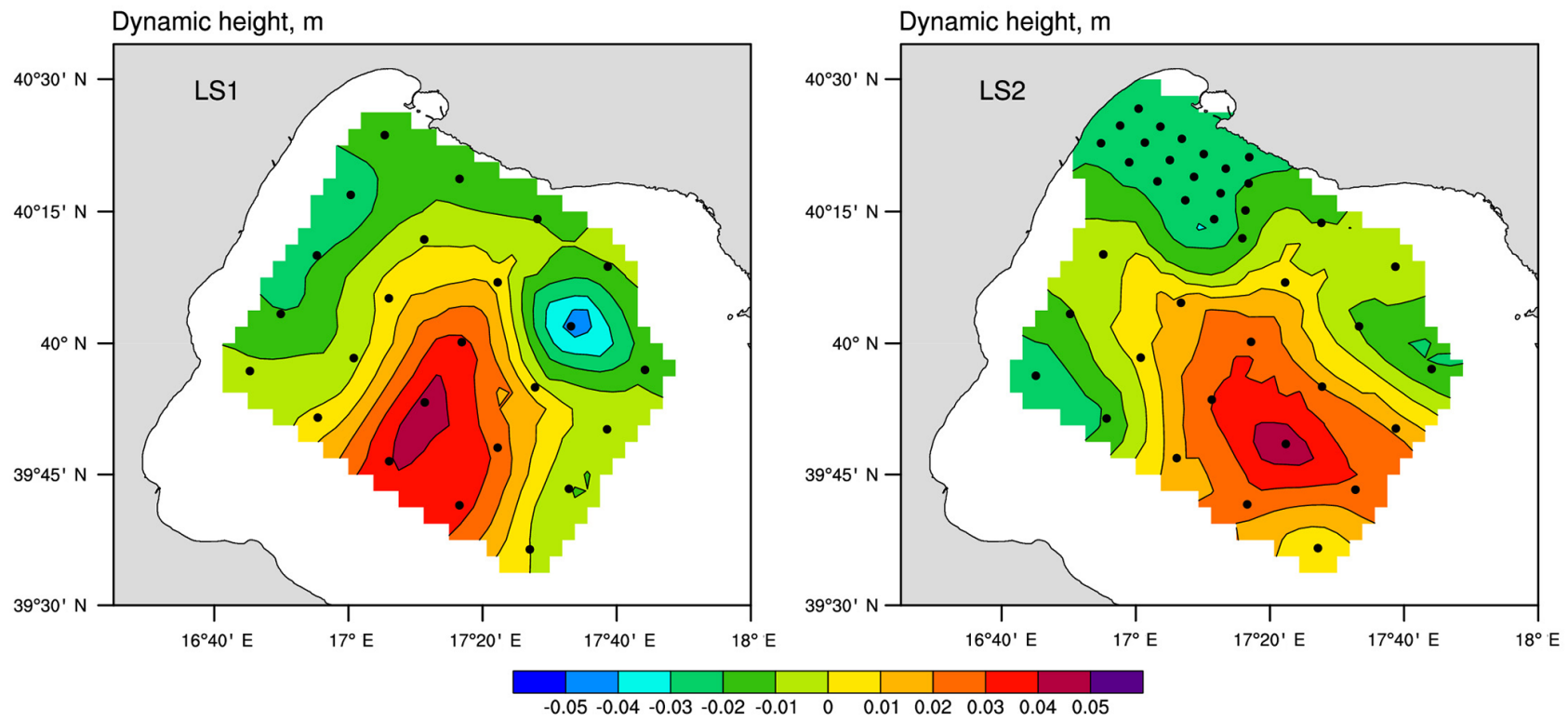

Figure 14. Dynamic height at $10 \mathrm{~m}$ with respect to $100 \mathrm{~m}$ reference level. Left panel: LS1. Right panel: LS2 + CS1.

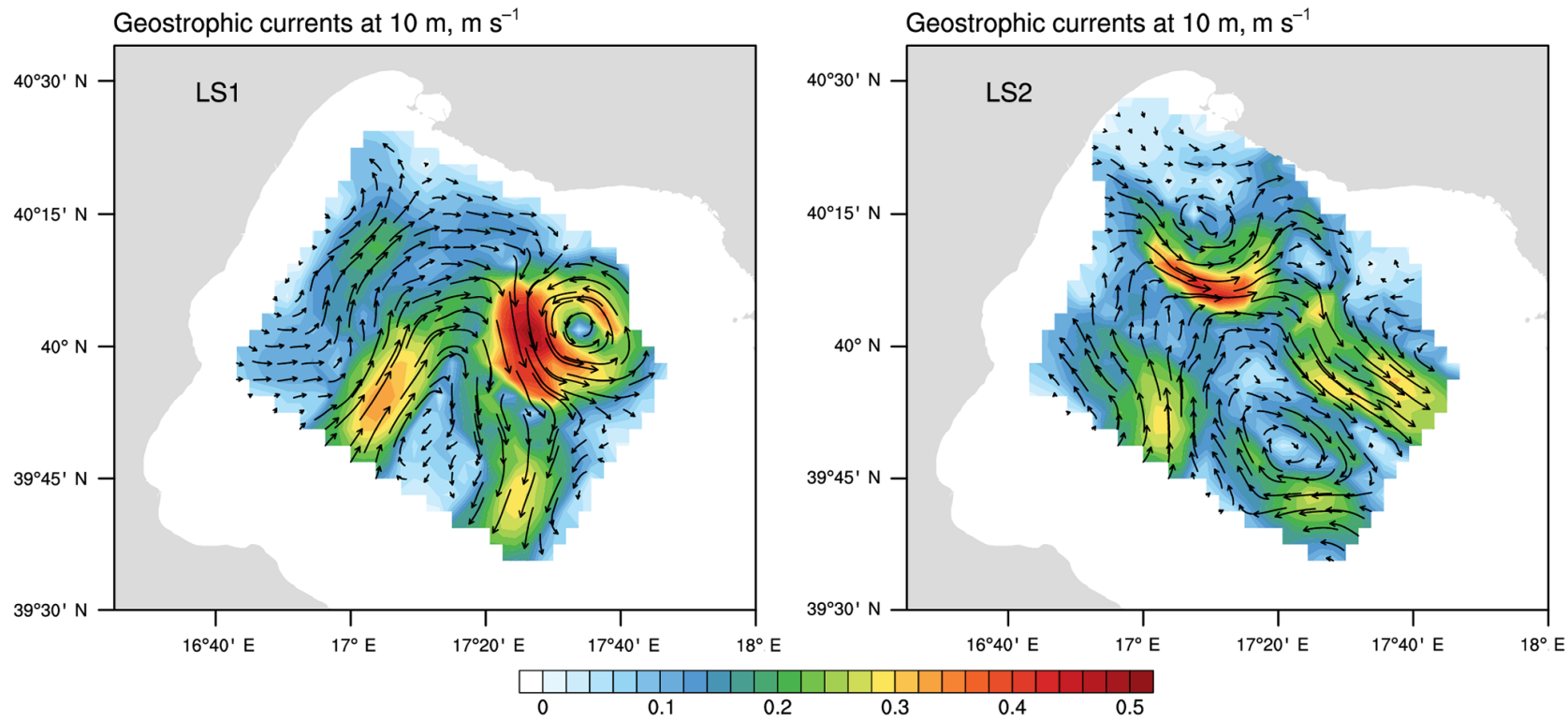

Figure 15. Geostrophic current velocities at $10 \mathrm{~m}$ with respect to $100 \mathrm{~m}$ for LS1 (left top panel) and LS2 (right top panel).

The water mass analysis for LS1, LS2 and CS1 showed that the vertical thermohaline structure is dominated by four water mass types: the first one belonging to the surface, down to $30 \mathrm{~m}$, characterized by relatively fresh and warm waters; the second one characterizing the thermocline; the third recognizable as MLIW with subsurface temperature and salinity maxima; and the fourth a deep water mass probably of Adriatic origin. The water column is highly stratified (BruntVäisälä frequency of the order of 10 cycles $^{-1}$ ) and the seasonal thermocline is located between 30 and $100 \mathrm{~m}$. Furthermore a precipitation event occurred between LS1 and LS2 which lowered the surface salinity of $0.1 \mathrm{PSU}$, concomitantly changing the mixed layer temperatures of $0.5^{\circ} \mathrm{C}$ due to a large wind event (Fig. 7).

The mapping of the temperature and salinity structures was carried out by objective analysis, calibrated for the specific survey sampling scheme. Starting with the mixed layer mapping, it emerged that large-scale frontal structures changed between LS1 and CS1 + LS2 cruises due to the growth and decay of small-scale, mixed layer intensified cyclonic eddies. The middle thermocline circulation, temperature and salinity structure of the Gulf of Taranto is dom- 
inated by an anticyclonic large-scale gyre. Its periphery is dominated by upwelling as shown by the low temperature and high salinity waters, especially on the northeastern side of the Gulf of Taranto. The gyre rim current was hydrodynamically unstable, generating frontogenesis and rim current segment intensifications. Two cyclonic eddy centers (C3 and C4) grew and decayed between LS1 and LS2. One of them could be classified as submesoscale, due to its small size, captured only by the finer sampling scheme of the CS1 survey.

The mapping of temperature and salinity fields in the Mar Grande suggests several density compensating fronts and generally low stratification, presumably connected to the estuarine vertical circulation.

The instability of gyre rim currents and/or large mesoscale eddy field borders has been studied in the past (Mc Williams et al., 1983; Pinardi et al., 1987; Staneva et al., 2001) and more recently for submesoscale generating fronts (Hamlington et al., 2014). The instabilities of rim currents connected to temperature frontal structures generate eddies, which are due to cyclogenetic processes such as mixed baroclinicbarotropic instabilities. In our case the observations show that instabilities occur in a week-long time frame and most importantly modulate the upwelling phenomena at the openocean-shelf-area interface, a mechanism that could be very important to support good environmental conditions in the near coastal regions. Numerical modeling studies have now started to understand the vorticity and energy dynamics of the flow field observed in this experiment.
In conclusion, regular sampling networks can capture most of the significant ocean variability if adequately calibrated for station resolution from the open ocean to the shelf and coastal-harbor scale. More observations will be required to map the seasonal variability of the anticyclonic gyre, the structure of the upwelling areas and their influence on the coastal ecosystem and the submesoscale flow field captured for the first time in this experiment.

This paper's MREA sampling methodology could be also used to collect data in order to respond to environmental emergencies, such as oil spills or other pollutant dispersal. If the location of the source of pollution is known, the CS1 sampling strategy could be carried out in 1 day, and forecasting models could have the initial condition adjusted to the measured fields through data assimilation, improving the forecast skill. Thus this paper has also put the basis for a protocol of in situ data collection that could support emergency management at sea.

\section{Data availability}

The CTD data are available at the following link: http://mrea. sincem.unibo.it/index.php/experiments/mrea14. The objective analysis codes can be made available at any time upon request to nadia.pinardi@unibo.it. 


\section{Appendix A: Objective analysis mapping}

Objective analysis is a least square estimation method, also known as Gauss-Markov filter, that map non-regularly spaced observations into a regular grid. It was applied for the first time in oceanography by Bretherton et al. (1976) and Carter and Robinson (1987). The assumptions are that the statistics of the interpolated field is stationary and homogeneous.

The problem can be stated as follows: given $\varphi_{r}$ observations at $\boldsymbol{x}_{r}=\left(x_{r}, y_{r}\right)$ locations irregularly spaced with $r=1, \ldots N$, we would like to estimate the field $\hat{\theta}_{x}$ in a regular $\boldsymbol{x}$ grid. Assuming that $\varphi_{\mathrm{r}}=\theta_{r}+\varepsilon_{r}$, where $\theta_{r}$ is the true field and $\varepsilon_{r}$ is the measurement error, the least square estimate is

$\hat{\theta}_{\boldsymbol{x}}=\tilde{\theta}+\sum_{r=1}^{N} C_{\boldsymbol{x} r}\left\{\sum_{s=1}^{N} A_{r s}^{-1}\left(\varphi_{s}-\tilde{\theta} \cdot\right)\right\}$

The correlation functions are defined as

$A_{r s}=\left\langle\varphi_{r} \varphi_{s}\right\rangle=F\left(\boldsymbol{x}_{\mathrm{r}}-\boldsymbol{x}_{s}\right)+E \delta_{r s}$,

and

$C_{\boldsymbol{x} r}=\left\langle\varphi_{\boldsymbol{x}} \varphi_{r}\right\rangle=F\left(\boldsymbol{x}-\boldsymbol{x}_{\mathrm{r}}\right)$,

where brackets indicate the ensemble mean. $F$ is commonly written as

$F(r)=\left(1-\frac{r^{2}}{b^{2}}\right) e^{-\frac{r^{2}}{2 a^{2}}}$,

with $r^{2}=x^{2}+y^{2}$ being the square of the distance between two points and $a, b$ the decorrelation and decay lengths respectively. $E$ is the measurement error variance, $\left\langle\varepsilon_{r} \varepsilon_{s}\right\rangle=$ $E \delta_{r s}$, which is taken in all our calculation to be $10 \%$ of the field variance, assuming to be dominated by the representativeness error.

Table A1. Objective analysis mapping parameters.

\begin{tabular}{lrrrr}
\hline Survey & $\begin{array}{r}\text { Grid size } \\
(\text { degrees, km) }\end{array}$ & $\begin{array}{r}a \\
(\mathrm{~km})\end{array}$ & $\begin{array}{r}b \\
(\mathrm{~km})\end{array}$ & $\begin{array}{r}\text { Radius of } \\
\text { influence }\end{array}$ \\
\hline MG1 & $1 / 512(\sim 200 \mathrm{~m})$ & 2 & 1 & $1 \mathrm{~km}$ \\
LS1 \& LS2+CS1 & $1 / 32(\sim 3 \mathrm{~km})$ & 25 & 15 & $20 \mathrm{~km}$ \\
\hline
\end{tabular}

$\widetilde{\theta}$ is the field mean estimated from the observations using the following weighted average:

$$
\widetilde{\theta}=\frac{1}{\sum_{r, s}^{N} A_{r s}^{-1}} \sum_{r, s}^{N} A_{r s}^{-1} \varphi_{s}
$$

The correlation functions used for mapping depends on the observational sampling; i.e., sparse observations will need to consider relatively larger decorrelation scales with respect to denser networks which will require smaller values of $a$. The $a, b$ values used in this paper are listed in Appendix Table A1 and different ones were chosen for the three sampling schemes used, for LS1, LS2, CS1 and MG1. A radius of influence is also used within which the $N$ observations are chosen for each estimated grid point which is also listed in Table A1.

The interpolated field percentage error variance is written as (Bretherton, 1976)

$$
\frac{\left(\theta_{\boldsymbol{x}}-\hat{\theta}_{\boldsymbol{x}}\right)^{2}}{C_{x x}}=1-\frac{\sum_{r, s}^{N} C_{x r} A_{r s}^{-1} C_{x s}}{C_{x x}}+\frac{\left(1-\sum_{r, s}^{N} C_{x s} A_{s r}\right)^{2}}{C_{x x} \sum_{r, s}^{N} A_{r s}^{-1}} .
$$

The square root of Eq. (A6) is given in Fig. A1 for the LS1, LS2 + CS1 and MG1 surveys. The growth of errors from the station points outward depends on the correlation parameters $a, b$ in Eq. (A4). All our mapped fields were masked in order not to display areas with errors larger than $50 \%$ for LS1, LS2 + CS1 and larger than $20 \%$ for MG1. 

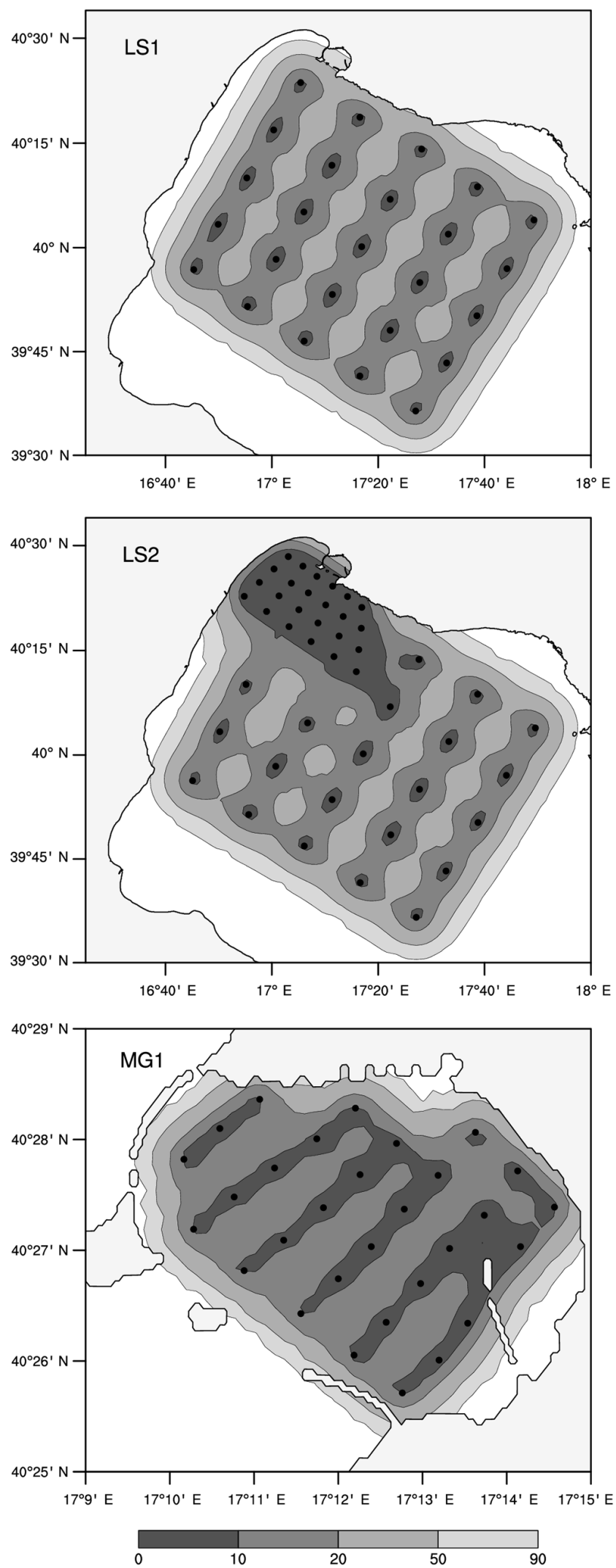

Figure A1. Objective analysis percentage error field for the three surveys using the parameters of Table A1 (units are \%). 
Acknowledgements. This paper was partially funded by the PON Project TESSA "Technologies for Situational Sea Awareness", a Italian Ministry of Research RITMARE project. We would like to thank Vincenzo De Palmis of IAMC-CNR for his logistic support.

Edited by: R. Archetti

Reviewed by: two anonymous referees

\section{References}

Bonavita, M., Torrisi, L., and Marcucci, F.: The ensemble Kalman filter in an operational regional NWP system: Preliminary results with real observations, Q. J. R. Meteorol. Soc., 134, 1733-1744, 2008.

Bouffard, J., Renault, L., Ruiz, S., Pascual, A., Dufau, C., and Tintoré, J.: Sub-surface small-scale eddy dynamics from multisensor observations and modeling, Prog. Oceanogr., 106, 62-79, 2012.

Bretherton, F.,P., Davis, R. E., and Fandry, C. B.: A technique for objectiveanalysis and design of oceanographic experiments, Deep-Sea Res., 23, 559-582, 1976.

Carter, E. F. and Robinson, A. R.: Analysis models for the estimation of oceanic fields, J. Atmos. Ocean. Technol., 4, 49-74, 1987.

Cessi, P., Pinardi, N., and Lyubartsev, V.: Energetics of Semienclosed Basins with Two-Layer Flows at the Strait, J. Phys. Oceanogr., 44, 967-979, doi:10.1175/JPO-D-13-0129.1, 2014.

Federico, I., Pinardi, N., Oddo, P., Lecci, R., and Mossa, M.: Coastal ocean forecasting with an unstructured-grid model in the Southern Adriatic Northern Ionian Sea, this Special Issue, 2016.

Frolov, S., Garau, B., and Bellingham, J.: Can we do better than the grid survey: Optimal synoptic surveys in presence of variable uncertainty and decorrelation scales, J. Geophys. Res.-Oceans, 119, 5071-5090, doi:10.1002/2013JC009521, 2014.

Gaeta, M, G., Samaras, A., Federico, I., and Archetti, R.: A coupled wave-3D hydrodynamics model of the Taranto Sea (Italy): a multiple nesting approach, this special issue, 2016.

Guarnieri, A., Pinardi, N., Oddo, P., Bortoluzzi, G., and Ravaioli, M.: Impact of tides in a baroclinic circulation model of the Adriatic Sea, J. Geophys. Res.-Oceans, 118, 166-183, doi:10.1029/2012jc007921, 2013.

Hamlington, P. E., Van Roekel, L. P., Fox-Kemper, B., Julien, K., and Chini, G. P.: Langmuir-Submesoscale Interactions: Descriptive Analysis of Multiscale Frontal Spin-Down Simulations, J. Phys. Oceanogr., 44, 2249-2272, 2014.
Hecht, A., Pinardi, N., and Robinson, A. R.: Currents, Water Masses, Eddies and Jets in the Mediterranean Levantine Basin, J. Phys. Oceanogr., 18, 1320-1353, 1998.

Lermusiaux, P. F. J.: Adaptive modeling, adaptive data assimilation and adaptive sampling, Physica D, 230, 172-196, 2007.

McWilliams, J. C., Brown, E. D., Bryden, H. L., Ebbesmeyer, C. C., Elliot, B. A., Heinmiller, R. H., Hua, B. L., Leaman, K. D., Lindstrom, E. J., Luyten, J. R., McDowell, S. E., Owens, W. B., Perkins, H., Price, J. F., Regier, L., Riser, S. C., Rossby, H. T., Sanford, T. B., Shen, C. Y., Taft, B. A., and Van Leer, J. C.: The local dynamics of eddies in the western North Atlantic. In: Eddies in Marine Science, edited by: Robinson, A. R., SpringerVerlag, Berlin Heidelberg, 92-113, 1983.

Oddo, P., Bonaduce, A., Pinardi, N., and Guarnieri, A.: Sensitivity of the Mediterranean sea level to atmospheric pressure and free surface elevation numerical formulation in NEMO, Geosci. Model Dev., 7, 3001-3015, doi:10.5194/gmd-7-30012014, 2014.

Pinardi, N. and Robinson, A. R.: Dynamics of deep thermocline jets in the Polymode Region, J. Phys. Oceanogr., 17, 1163-1188, 1987.

Pinardi, N., Zavatarelli, M., Adani, M., Coppini, G., Fratianni, C., Oddo, P., Simoncelli, S., Tonani, M., Lyubartsev, V., and Dobricic, S.: The Mediterranean Sea large scale low frequency ocean variability from 1987 to 2007: a retrospective analysis, Prog. Oceanogr., 132, 318-332, doi:10.1016/j.pocean.2013.11.003, 2015.

Robinson, A. R. and Shellschopp, J.: Rapid Assessment of the Coastal Ocean Environment, in: Pinardi, N. and Woods, J., Ocean Forecasting, Springer-verlag, 2002.

Staneva, J. V., Dietrich, D. E., Stanev, E. V., and Bowman, M. J.: Rim current and coastal eddy mechanisms in an eddy-resolving Black Sea general circulation model, J. Mar. Syst., 31, 137-157, 2001.

Talley, L. D., Pickard, G. L., Emery, W. J., and Swift, J. H.: Descriptive Physical Oceanography: an introduction, Academic Press, Elsevier, 2011.

Theocharis, A., Georgopoulos, D., Lascaratos, A., and Nittis, K.: Water masses and circulation in the central region of the Eastern Mediterranean: Eastern Ionian, South Aegean and Northwest Levantine, 1986-1987, Deep-Sea Res. Pt. II, 40, 1121-1142, doi:10.1016/0967-0645(93)90064-T, 1993.

Thomas, L. N., Tandon, A., and Mahadevan, A.: Submesoscale Processes and Dynamics, in: Ocean Modeling in an Eddying Regime, edited by: Hecht, M. W. and Hasumi, H., American Geophysical Union, Washington, DC, doi:10.1029/177GM04, 2008. 